\title{
A Linguística Aplicada como aliada na promoção de práticas pedagógicas inclusivas
}

\author{
Aline Aquino Vieira \\ Universidade Federal do Rio de Janeiro - UFRJ
}

\begin{abstract}
Resumo
A educação inclusiva tem conquistado cada vez mais espaço nas escolas brasileiras, o que representa um importante passo para o empoderamento e a consolidação da autonomia das pessoas com necessidades especiais. Nesse promissor contexto, professores enfrentam grandes desafios para lidar com as especificidades da heterogeneidade de seus alunos. Muitos ainda não se sentem preparados e seguros para desenvolver as potencialidades de seus alunos, pois sua formação é deficitária e faltam pesquisas acessíveis que contemplem e proponham práticas pedagógicas inclusivas. $\mathrm{O}$ objetivo desse artigo é propor o maior engajamento da Linguística Aplicada com essas questões, enfatizando que o sujeito com necessidades especiais é também o sujeito que devemos contemplar em nossas pesquisas.
\end{abstract}

Palavras-chave: Educação inclusiva. Linguística Aplicada. Formação docente.

\begin{abstract}
Inclusive education has gained more space in Brazilian schools, which represents an important step towards empowering and strengthening the autonomy of people with special needs. In this promising context, teachers face big challenges in dealing with the specifics of the heterogeneity of their students. Many of them still do not feel prepared and confident enough to develop the potential of their students, because these teachers have had a subpar special needs education and because there is a lack of accessible research that addresses and offers inclusive teaching practices. The aim of this paper is to propose the greater engagement of Applied Linguistics with these issues, emphasizing that the individual with special needs is also the individual we should consider in our research.
\end{abstract}

Keywords: Inclusive education. Applied Linguistics. Teacher education.

\section{CONSIDERAÇÕES INICIAIS}

Pertencimento: saber o lugar que ocupamos no mundo e qual papel exercemos. Ser protagonista de nossas próprias vidas, agir autonomamente, trocar, influenciar e ser influenciado através da interação com o outro. Tais ações são imprescindíveis para a vida em sociedade e para o exercício da cidadania. Trazem dignidade às pessoas.

Todos são merecedores de condições ideais para seu pleno desenvolvimento. Sabemos que há educadores engajados em todo o país em uma crescente luta por 
melhorias na educação. Debates têm sido promovidos, atraindo a atenção das mídias e dos políticos para o tema. Em linhas gerais, há um longo caminho a ser percorrido e uma grande distância a ser diminuída. Contudo, quando tratamos da Educação Inclusiva, os obstáculos se apresentam em maior escala, considerando a falta de informação, as dificuldades infra-estruturais, a formação docente, a elaboração do currículo, a avaliação e a escassez de materiais e recursos didáticos preparados com essa finalidade ou que possam ser adaptados de modo a promover a acessibilidade pedagógica necessária, conforme afirmam os Parâmetros Curriculares Nacionais para Educação Inclusiva $^{1}$ (BRASIL, 1998, p. 18):

\begin{abstract}
A prática escolar tem evidenciado o que pesquisas científicas vêm comprovando: os sistemas educacionais experimentam dificuldades para integrar o aluno com necessidades especiais. Revelam os efeitos dificultadores de diversos fatores de natureza familiar; institucionais e socioculturais.
\end{abstract}

Por melhores intenções que os professores possuam, em sua grande maioria, não se sentem preparados para lidar com o aluno com necessidades educacionais especiais, embora disciplinas sobre o tema já figurem nos currículos contemporâneos de licenciatura. O professor necessita estar preparado para lidar com seu variado grupo de alunos, que apresentam ou não dificuldades ou necessidades especiais. E isso não é tarefa fácil. Os PCN-EI apontam a necessidade da qualificação do professor para a Educação Inclusiva:

$\mathrm{O}$ que se figura de maneira mais expressiva ao se pensar na viabilidade do modelo de escola inclusiva para todo o país no momento é a situação dos recursos humanos, especificamente dos professores das classes regulares, que precisam ser efetivamente capacitados para transformar sua prática educativa. A formação e a capacitação docente impõem-se como meta principal a ser alcançada na concretização do sistema educacional que inclua a todos, verdadeiramente. (BRASIL, 1998, p.17)

Dadas as nuances do caso a caso, a heterogeneidade dos grupos e a necessidade de adaptação curricular, promover a Educação Inclusiva é desafiador, porém pode ser igualmente recompensador quando há a consciência do papel emancipador que o professor pode exercer nas vidas de seus alunos. Trata-se do empoderamento de pessoas com necessidades especiais.

Poucas pesquisas na área, sobretudo no campo da Linguística Aplicada, dificultam a difusão de informações. O escasso diálogo entre a teoria e a prática tão necessário é mantido nas esferas acadêmicas e raramente chega às salas de aula. É lá

\footnotetext{
${ }^{1}$ Parâmetros Curriculares Nacionais - Adaptações Curriculares - Estratégias para a educação de alunos com necessidades educacionais especiais. Usaremos a sigla PCN-EI como referência.
} 
que se encontram as angústias, as perguntas sem resposta e a defasagem na formação docente. É latente a necessidade de novas pesquisas na área. Um exemplo atual: No XI Congresso Brasileiro de Linguística Aplicada, realizado na UFMS (julho de 2015) foram submetidos 600 trabalhos, sendo apenas 14 relativos à Educação Inclusiva. Desses 14 trabalhos, 11 tratavam de surdos. Além do baixo quantitativo, outras necessidades especiais deixaram de ser contempladas. Os PCN-EI legitimam a importância da Educação Inclusiva e ressaltam a necessidade de pesquisas na área dada sua diversidade:

\begin{abstract}
A inclusão escolar constitui, portanto, uma proposta politicamente correta que representa valores simbólicos importantes, condizentes com a igualdade de direitos e de oportunidades educacionais para todos, em um ambiente educacional favorável. Impõe-se como uma perspectiva a ser pesquisada e experimentada na realidade brasileira, reconhecidamente ampla e diversificada. (BRASIL, 1998, p. 17)
\end{abstract}

Legitimando a necessidade do engajamento e de mais pesquisas na área, esse artigo busca uma reflexão quanto às crenças e práticas dos docentes que atuam na Educação Inclusiva, buscando oferecer um espaço para que sejam ouvidas suas vozes. Na primeira parte, apresentaremos um breve histórico da Educação Inclusiva no Brasil, contemplando também a legislação vigente, reconhecidamente como uma das mais completas no mundo. Estabeleceremos também sua relação com o campo da Linguística Aplicada. Na segunda parte, apresentaremos a fundamentação teórica desse estudo. Na terceira parte detalharemos a metodologia empregada para a análise dos dados gerados. $\mathrm{Na}$ quarta parte nos dedicaremos a analisar as vozes de professores que atuam na Educação Inclusiva, conhecendo suas crenças e anseios. Nas considerações finais, apresentaremos nossas impressões a partir desse diálogo com docentes que atuam no contexto da Educação Inclusiva.

\title{
A EDUCAÇÃO INCLUSIVA NO BRASIL
}

Como pontapé inicial para a pesquisa aqui proposta, é imprescindível o levantamento de informações relacionadas ao histórico e à legislação brasileira acerca da Educação Inclusiva (EI). Sendo assim, recorremos a vários documentos para nos embasar, buscando entender as raízes da EI no Brasil e os desdobramentos sofridos ao longo do tempo, exercendo o papel intrínseco ao de professor: o de pesquisador.

A Política Nacional de Educação Especial na Perspectiva da Educação Inclusiva, elaborada pelo MEC (BRASIL, 2007), é um documento de grande valor para a 
contextualização acerca da educação para crianças com necessidades especiais no Brasil. Nele estão reunidas informações históricas, marcos e estatísticas, além da síntese de objetivos e diretrizes para essa modalidade educativa. De acordo com esse documento (BRASIL, 2007, p. 2), o atendimento às pessoas com necessidades educacionais especiais teve início na época do Império e por muito tempo perpetuou-se a ideia de que essas práticas educativas deveriam acontecer paralelamente à educação comum devido às estruturas rígidas dos sistemas de ensino. Afirma que:

\begin{abstract}
Essa concepção exerceu impacto duradouro na história da educação especial, resultando em práticas que enfatizavam os aspectos relacionados à deficiência, em contraposição à sua dimensão pedagógica. $\mathrm{O}$ desenvolvimento de estudos no campo da educação e dos direitos humanos vem modificando os conceitos, as legislações, as práticas educacionais e de gestão, indicando a necessidade de se promover uma reestruturação das escolas de ensino regular e da educação especial. (BRASIL, 2007, p.15)
\end{abstract}

Rompendo com esse paradigma, em 1994, a Declaração de Salamanca, proclamou que as escolas regulares deveriam receber todos os alunos, independentemente de sua condição, com necessidades especiais ou não, contribuindo para o combate a atitudes discriminatórias e a igualdade de oportunidades.

A escola é um direito de todos, conforme o assegurado pelo artigo 205 da Constituição Federal Brasileira de 1988. É no artigo 208 em que a Educação Inclusiva é citada enquanto dever do Estado, cabendo a ele assegurar "atendimento educacional especializado aos portadores de deficiência, preferencialmente na rede regular de ensino". O mesmo é tratado pela Lei de Diretrizes e Bases (LDB) da Educação Brasileira (BRASIL, 1996), alterada pela Lei 12.796, sancionada em 4 de abril de 2013, no inciso III do artigo $4^{\circ}$, que afirma que o Estado deve oferecer "atendimento educacional especializado gratuito aos educandos com deficiência, transtornos globais do desenvolvimento e altas habilidades ou superdotação, transversal a todos os níveis, etapas e modalidades, preferencialmente na rede regular de ensino". Também no capítulo V, dedicado a Educação Especial, são salientados os direitos dos educandos, enfatizando serviços de apoio especializados nas escolas regulares para "atender às peculiaridades da clientela de educação especial" e dos sistemas de ensino que deverão assegurar "currículos, métodos, técnicas, recursos educativos e organização específicos, para atender às suas necessidades" e "professores com especialização adequada em nível médio ou superior, para atendimento especializado, bem como professores do ensino regular capacitados para a integração desses educandos nas classes comuns". Outro fator de destaque é a preocupação com a qualidade de vida e autonomia dos 
educandos promovendo "educação especial para o trabalho, visando a sua efetiva integração na vida em sociedade, inclusive condições adequadas para os que não revelarem capacidade de inserção no trabalho competitivo, mediante articulação com os órgãos oficiais afins, bem como para aqueles que apresentam uma habilidade superior nas áreas artística, intelectual ou psicomotora", corroborando com a visão apresentada no início do documento no inciso XI do artigo $3^{\circ} \mathrm{em}$ que é proposta, "vinculação entre a educação escolar, o trabalho e as práticas sociais".

Os Parâmetros Curriculares Nacionais (BRASIL, 1997) trazem orientações para a promoção da Educação Inclusiva, através da liberdade para a adaptação curricular, salientando que não há respostas fixas, mas "implica, sim, a convicção de que o aluno e a escola devem se aprimorar para alcançar a eficiência da educação a partir da interatividade entre esses dois atores" (p. 16). Reconhecem também os desafios a serem superados, quanto à formação docente, quanto à diversidade nas salas de aula e os recursos a serem utilizados. Segundo os PCN (BRASIL, 1997, p. 18):

\begin{abstract}
A prática escolar tem evidenciado o que pesquisas científicas vêm comprovando: os sistemas educacionais experimentam dificuldades para integrar o aluno com necessidades especiais. Revelam os efeitos dificultadores de diversos fatores de natureza familiar, institucionais e socioculturais. A maioria dos sistemas educacionais ainda baseia-se na concepção médicopsicopedagógica quanto à identificação e ao atendimento de alunos com necessidades especiais. Focaliza a deficiência como condição individual e minimiza a importância do fator social na origem e manutenção do estigma que cerca essa população específica. Essa visão está na base de expectativas massificadas de desempenho escolar dos alunos, sem flexibilidade curricular que contemple as diferenças individuais.
\end{abstract}

Nas últimas décadas significativas mudanças aconteceram na organização da Educação Básica brasileira, dentre elas a obrigatoriedade do Ensino Fundamental em 9 anos. Desse modo, houve a necessidade da atualização das Diretrizes Curriculares Nacionais para a Educação Básica, estabelecendo a base educacional comum, responsável pela orientação, articulação, desenvolvimento e avaliação das propostas pedagógicas de todas as redes de ensino brasileiras (BRASIL, 2013). Segundo esse documento (p. 42), "A Educação Especial é uma modalidade de ensino transversal a todas as etapas e outras modalidades, como parte da educação regular, devendo ser prevista no projeto político pedagógico da unidade escolar." Concluindo-se que todas as escolas deverão estar preparadas para receber alunos especiais e adaptar-se para atender suas necessidades e desenvolver suas potencialidades. 


\title{
AS VOZES DO SUL: EDUCAÇÃO INCLUSIVA E A LINGUÍSTICA APLICADA
}

Muitas são as preocupações acerca do desenvolvimento de crianças especiais, que vão desde a aquisição da fala, agressividade, problemas de motricidade à promoção da autonomia. Uma grande dúvida que assola as famílias é em relação ao momento em que faltarem aos seus filhos. Estariam eles preparados para a vida em sociedade de forma autônoma? A Declaração de Salamanca (UNESCO, 1994) alerta quanto ao preparo para esse momento de transição:

\begin{abstract}
Jovens com necessidades educacionais especiais deveriam ser auxiliados no sentido de realizarem uma transição efetiva da escola para o trabalho. Escolas deveriam auxiliá-los a se tornarem economicamente ativos e provê-los com as habilidades necessárias ao cotidiano da vida, oferecendo treinamento em habilidades que correspondam às demandas sociais e de comunicação e às expectativas da vida adulta. Isto implica em tecnologias adequadas de treinamento, incluindo experiências diretas em situações da vida real, fora da escola.
\end{abstract}

Nesse sentido, a escola deve objetivar a consolidação da autonomia, propiciando formação e preparo para que as pessoas com necessidades especiais tenham acesso aos letramentos essenciais para interagirem em suas trajetórias, em condições de igualdade com os demais membros da comunidade. Tal meta não é facilmente alcançável, dada a complexidade da prática do letramento considerando as limitações e anseios de cada ser humano, independentemente de ele ter necessidades especiais ou não. Além disso, também são entraves os problemas anteriormente citados como a falta de preparo dos professores, escassez de materiais didáticos e infra-estrutura apropriada. É fundamental a atuação autônoma do professor na descristalização de conceitos, na reflexão quanto à práxis educativa e na elaboração e utilização de materiais didáticos que corroborem para os letramentos dos aprendizes. A partir dessa postura mais engajada (e por que não?), confiante, estaremos mais perto da promoção da autonomia e do empoderamento de nossos alunos especiais. Segundo Kenny (1993, p. 436)

A autonomia é, portanto, um conceito vital para a educação, pois é o único
aspecto de ser um aluno sobre o qual a educação pode se concentrar sem
interferências prejudiciais, ou efeitos de condicionamento. Sob este ponto de
vista, a autonomia não é apenas a liberdade de escolher entre materiais
didáticos e metodologias, ou até mesmo para negociar um plano de estudos.
É mais importante do que isso. Adaptando algumas famosas palavras de Carl
Rogers, autonomia é a liberdade de aprender e a oportunidade de se tornar
uma pessoa.

\footnotetext{
${ }^{2}$ Tradução nossa. Original: Autonomy is therefore a vital concept for education, for it is the only aspect of a learner's being upon which education can focus without detrimental interference, or conditioning effects. From this point of view, autonomy is not only the freedom to choose among materials and
} 
Para a reversão do quadro atual de desinformação e insegurança por parte dos educadores é necessário ampliar a realização e divulgação de pesquisas que dialoguem mais com suas práticas e que possam se identificar com seus desafios cotidianos. Tal objetivo foi citado na Declaração de Salamanca (UNESCO, 1994):

estimular a comunidade acadêmica no sentido de fortalecer pesquisa, redes de trabalho e o estabelecimento de centros regionais de informação e documentação e da mesma forma, a servir de exemplo em tais atividades e na disseminação dos resultados específicos e dos progressos alcançados em cada país no sentido de realizar o que almeja a presente Declaração.

Por isso, ressalta-se mais uma vez a necessidade de maior número de pesquisas na área de Educação Inclusiva, que contemplem essa relação entre teoria e prática, sobretudo no campo da Linguística Aplicada (LA). Moita Lopes (2006, p.100-101) propõe que a LA seja "uma área que explode a relação entre teoria e prática" afirmando que:

Em uma LA que quer falar à vida contemporânea é essencial, não a
teorização elegantemente abstrata que ignora a prática, mas uma teorização
em que teoria e prática sejam conjuntamente consideradas em uma
formulação do conhecimento na qual a teorização pode ser muito mais um
trabalho de bricolage, tendo em vista a multiplicidade dos contextos sociais e
daqueles que os vivem. Arrolo motivos de natureza epistemológica, mas que,
claramente, têm implicações de natureza ética ao integrar "as vozes do Sul",
embora seja possível nos questionar também se é possível separar
epistemologia e ética.

Moita Lopes (2006, p. 101-103) também desconstrói a visão do sujeito social hegemônico enquanto objeto de estudo da LA, buscando abrir "alternativas sociais com base nas e com as vozes dos que estão à margem" (p.86) ou ainda problematizando como a diversidade pode contribuir para a transformação social. Segundo Mushakoji (1999, p. 207, apud MOITA LOPES, 2006, p. 86),

Como aqueles que "vivenciam o sofrimento humano" com base em suas epistemes diferentes podem colaborar na construção de "uma sociedade mais humana, mais delicada com a natureza e com as pessoas" ou, pelo menos, na compreensão de tal sociedade?

É preciso refletir e repensar a educação hegemônica ainda predominante para que possamos vislumbrar respostas para essa questão proposta por Moita Lopes. Quando pensamos em heterogeneidade, ou em ouvir "as vozes do sul", como ele propõe, nos remetemos a priori a questões étnicas, sexualidade, gênero, classes, mas ainda tardamos em nos lembrar das pessoas com necessidades especiais que são tão ou mais marginalizadas que as demais minorias: são excluídas como se fossem invisíveis,

methodologies, or even to negotiate a syllabus. It is more important than this. To adapt some famous words of Carl Rogers, autonomy is the freedom to learn and the opportunity to become a person. 
são subestimadas com se os esforços educacionais fossem "perda de tempo" para seu desenvolvimento, discriminadas, convivendo com olhares desviados e taxadas como dignas de pena. Há não muito tempo atrás, a assistência às pessoas especiais foi considerada como um "ato de misericórdia", pois tudo que podia ser visto eram as deficiências que as pessoas possuíam. Segundo Vygotsky (2010, p.382):

O princípio da educação, que se concentrava nas mãos da beneficência, baseava-se nas ideias de que é necessário "ter piedade dos miseráveis", mantê-los com recursos sociais, ajudá-los a levar aos trancos e barrancos uma deplorável sobrevivência humana.(...) Neste caso, não se fazia nenhuma tentativa de ir além dos limites da conciliação com a deficiência, e a regra pedagógica básica era a adaptação da educação a essa deficiência e não a sua superação.

Ficou no passado esse enfoque nas deficiências e o momento atual urge pelo desenvolvimento das habilidades que cada um possui, buscando a superação das barreiras que são na maioria das vezes mais sociais e burocráticas do que as impostas pelas condições físicas ou mentais dessas pessoas. Segundo Vygotsky (2010, p. 381):

Com a organização correta da vida da criança e a diferenciação moderna das funções sociais, o defeito físico não pode, de maneira nenhuma, vir a ser para o deficiente a causa da completa imperfeição ou invalidez social. Tudo consiste apenas em que, nesses casos, os procedimentos educativos devem ser individualizados em função de cada caso particular, e através do método da compensação, por um lado, e da adaptação, por outro, o problema pode ser resolvido de forma indolor. Numa educação racional, pode-se conservar para o deficiente toda a soma do seu valor social de tal forma que a influência da sua deficiência possa ser quase reduzida a zero.(...) O milagre da educação social consiste em que ela ensina o deficiente a trabalhar, o mudo a falar, o cego a ler. Mas esse milagre deve ser entendido como um processo absolutamente natural de compensação educativa das deficiências.

Para a transposição dos obstáculos que inviabilizam a atuação social das pessoas com necessidades especiais, devem atuar as escolas inclusivas enquanto espaço de heterogeneidade e dialogismo. O compartilhamento do espaço e a sinergia entre alunos neurotípicos e especiais contribui para a quebra de estereótipos, a tolerância, o respeito, empatia e o desenvolvimento do agir autônomo, fundamentais para a transformação social.

\section{A PEDAGOGIA INCLUSIVA}

A Educação Inclusiva envolve os alunos e suas famílias, professores, materiais didáticos e a sociedade. Isso significa que expectativas e sentimentos estão envolvidos no processo de ensino e aprendizagem. O professor, além de ser um co-construtor de 
conhecimento, exerce uma função de acolhimento para alunos e familiares, o que requer envolvimento e empatia.

A inclusão não se trata somente de construção de conhecimentos escolares adaptados para os alunos com necessidades educacionais especiais ou de socialização. É preciso que os conceitos construídos dialoguem com a vida cotidiana, de modo a contribuir para a promoção da autonomia das pessoas, priorizando a função formativa da escola em detrimento da informativa. Como alicerce na edificação do conhecimento nas escolas, temos o currículo escolar.

Em minha experiência como professora e diretora de uma escola de Educação Infantil e Ensino Fundamental lido diariamente com os desafios da inclusão. Cada estratégia adotada é baseada em erros e acertos nos casos tratados individualmente. Ainda que o diagnóstico das crianças seja o mesmo, como a síndrome de Asperger, por exemplo, visto que acompanho três alunos com esse diagnóstico e que possuem perfis completamente diferentes, a responsividade dos alunos aos estímulos se dá de forma única, assim como nos casos dos alunos considerados neurotípicos. É importante ressaltar que não cabe à escola esperar que os alunos especiais se adaptem às suas propostas e currículos, mas ao contrário, deve esta adaptar-se para receber esses alunos, respeitando suas necessidades, investindo em suas potencialidades e ajustando seu modus operandi a partir de suas experiências. Os PCN-EI afirmam que:

\footnotetext{
Alguns educadores defendem que uma escola não precisa preparar-se para garantir a inclusão de alunos com necessidades especiais, mas tornar-se preparada como resultado do ingresso desses alunos. Indicam, portanto, a colocação imediata de todos na escola. Entendem que o processo de inclusão é gradual, interativo e culturalmente determinado, requerendo a participação do próprio aluno na construção do ambiente escolar que lhe seja favorável. (BRASIL, 1998, p. 18)
}

Dessa forma, um plano individualizado de educação deve ser traçado para cada aluno, realizando a adaptação curricular de modo a respeitar seus limites, necessidades, particularidades e ritmo de aprendizagem.

Reconheço que há muito a ser consolidado acerca da inclusão. Estamos navegando por águas ainda turbulentas para nós e é notório que por mais que existam documentos oficiais que norteiam a Educação Inclusiva e legislação que ampare os direitos dos alunos com necessidades educacionais especiais, nós educadores ainda nos sentimos inseguros para colocar em prática as propostas que nos são apresentadas. 


\section{ADAPTAÇÕES CURRICULARES PARA A EDUCAÇÃO INCLUSIVA}

De um modo geral, o currículo escolar é elaborado a partir do Projeto Político Pedagógico (PPP) de cada escola e busca contemplar as necessidades e aspectos identitários da comunidade onde está inserida. Cabe ao currículo orientar as atividades educacionais da escola, seus princípios filosóficos, estratégias de ensino e critérios de avaliação. Embora a escola possua autonomia para adaptá-lo a atender os alunos com necessidades educacionais especiais considerando-o sempre aberto, há dúvidas e incertezas, tanto em relação à seleção do conteúdo curricular como também na elaboração de materiais didáticos, uma vez que não há muitas opções disponíveis. É preciso determinar quais componentes são relevantes, como e quando serão ensinados e a de que forma e em qual momento acontecerá a avaliação, considerando também o tempo e o ritmo em que cada aluno concluirá as tarefas propostas. Os PCN-EI (BRASIL, 1998), ressaltam a liberdade da escola em flexibilizá-lo de modo que respeite as necessidades de cada aluno e contemple um plano de educação direcionado a atender especificamente demandas que corroborem para seu desenvolvimento e inclusão social, reconhecendo que essa adaptação não é uma tarefa simples.

Essas adaptações resguardam o caráter de flexibilidade e dinamicidade que o
currículo escolar deve ter, ou seja, a convergência com as condições do aluno
e a correspondência com as finalidades da educação na dialética de ensino e
aprendizagem. Não se colocam, portanto, como soluções remediativas para
"males diagnosticados" nos alunos, nem justificam a cristalização do ato
pedagógico igualmente produzido para todos na sala de aula. Do mesmo
modo, não defendem a concepção de que a escola dispõe sempre de uma
estrutura apropriada ou realiza um fazer pedagógico adequado a que o
educando deve se adaptar. Implica, sim, a convicção de que o aluno e a
escola devem se aprimorar para alcançar a eficiência da educação a partir da
interatividade entre esses dois atores. (BRASIL, 1998, p.16)

O currículo adaptado para o aluno com necessidades educacionais especiais deve condizer com a realidade escolar dos demais alunos de sua turma, de modo que ele participe das rotinas e metas compartilhadas por todos, respeitando e se beneficiando com a heterogeneidade do grupo. Segundo os PCN-EI:

Nesse contexto, a ajuda pedagógica e os serviços educacionais, mesmo os especializados - quando necessários - não devem restringir ou prejudicar os trabalhos que os alunos com necessidades especiais compartilham na sala de aula com os demais colegas. Respeitar a atenção à diversidade e manter a ação pedagógica "normal" parece ser um desafio presente na integração dos alunos com maiores ou menos acentuadas dificuldades para aprender. (BRASIL, p. 24) 
Ajustes serão necessários ao longo da realização das atividades, de acordo com as respostas obtidas. É preciso que os objetivos almejados sejam claros e realistas para que o progresso possa ser acompanhado diariamente e os resultados devidamente registrados. Após a definição dos conteúdos curriculares essenciais, descartando conteúdos menos relevantes e, consequentemente, ganhando mais tempo hábil para consolidação do que foi priorizado, é preciso focar no desenvolvimento das habilidades individuais e sociais do aluno, ressaltando suas potencialidades em detrimento de suas dificuldades e, para isso, a utilização de recursos e materiais didáticos diversificados é fundamental. Em teoria, a adaptação curricular funcionaria dessa forma. Mas o que nos dizem os professores que lidam com essa realidade diariamente? A adaptação curricular é tão simples assim?

\section{MATERIAIS DIDÁTICOS PARA A EDUCAÇÃO INCLUSIVA}

A elaboração e popularização de materiais didáticos impressos, concretos e digitais adaptáveis às necessidades especiais, seriam primordiais para que o professor tivesse subsídios para suas atividades. Cada aluno possui aspectos identitários que o tornam único e nenhum material didático é capaz de atingir a perfeição, por isso precisa ser sempre utilizado como ferramenta flexível pelo professor, corroborando também com a proposição da Declaração de Salamanca (UNESCO, 1994):

\footnotetext{
Toda criança possui características, interesses, habilidades e necessidades de aprendizagem que são únicas. Sistemas educacionais deveriam ser designados e programas educacionais deveriam ser implementados no sentido de se levar em conta a vasta diversidade de tais características e necessidades. Aqueles com necessidades educacionais especiais devem ter acesso à escola regular, que deveria acomodá-los dentro de uma Pedagogia centrada na criança, capaz de satisfazer a tais necessidades.
}

A realidade é que atualmente não há opções de livros didáticos que sejam facilmente adaptáveis para os alunos especiais. Em primeiro lugar, isso ocorre pela diversidade das necessidades especiais de cada aluno, físicas ou mentais. Em segundo lugar, embora a recomendação seja a de não fugir do conteúdo curricular da turma, que está sendo lecionado para os alunos neurotípicos, não é tão simples determinar o que tem condições de ser apreendido e o que é relevante para o cotidiano desse aluno. A solução então seria a criação de materiais personalizados para cada aluno, o que é trabalhoso e demanda tempo e experimentações. Na Educação Infantil e no $1^{\circ}$ segmento, a disponibilidade do professor é maior, pois o mesmo acompanha quase 
sempre uma turma durante o ano letivo. No $2^{\circ}$ segmento, o professor normalmente trabalha em várias escolas e o deslocamento e o grande número de alunos, avaliações para corrigir, etc, faz com que esse profissional esteja menos disponível para o planejamento e a elaboração dessas atividades personalizadas.

Na atualidade, as TICs (Tecnologias de informação e comunicação) têm sido empregadas na educação ainda com alguma timidez. Devido à interatividade que esses recursos possuem e suas variadas semioses, podem trazer um diferencial em relação ao uso do livro didático tradicional que possui a característica de ser estático, permitindo que essas adaptações sejam realizadas mais dinamicamente. Pesquisas vêm sendo desenvolvidas no campo da tecnologia assistiva, que pode ser definida como

uma área do conhecimento, de característica interdisciplinar, que engloba produtos, recursos, metodologias, estratégias, práticas e serviços que objetivam promover a funcionalidade, relacionada à atividade e participação, de pessoas com deficiência, incapacidades ou mobilidade reduzida, visando sua autonomia, independência, qualidade de vida e inclusão social. (CAT, 2007)

O emprego de tecnologias pode apresentar novas possibilidades para materiais didáticos. Contudo, há de se considerar que as TICs ainda são consideradas por uma parcela de educadores como difíceis de usar, estando fora de suas zonas de conforto. Segundo Paiva(2013, pg. 209-230)

Pelo que vimos até agora, a formação do professor para uso da tecnologia, raramente acontece de forma sistematizada. Isso não é diferente no Brasil, onde a formação tecnológica fica, geralmente, restrita a iniciativas individuais. (...) É comum entre os que advogam a apropriação das novas tecnologias na educação, o reconhecimento de que elas ainda podem intimidar muitos professores, apesar de acreditarem que o uso adequado da tecnologia por um professor bem formado pode beneficiar enormemente os aprendizes $(. .$.

Então, somado à desinformação acerca da Educação Inclusiva está a falta de intimidade com tecnologias, em parte pela falta de uma formação que integre as TICs à pratica docente e também por acomodação. São obstáculos que somente poderão ser superados pelos educadores, através de uma postura investigativa e mais ousada, que requer maior disponibilidade e dedicação.

\section{O PAPEL DO PROFESSOR-PESQUISADOR NA EDUCAÇÃO INCLUSIVA}

A prática docente requer bastante mobilização em pesquisas e investimentos para a formação continuada. Essas necessidades são potencializadas quando o professor atua na Educação Inclusiva, uma modalidade em que o ensino e a aprendizagem 
carecem de um planejamento individualizado para os alunos. Dessa forma, é preciso que o professor assuma uma postura de pesquisador para que possa observar, avaliar, desconstruir e construir suas próprias crenças e práticas. Segundo BortoniRicardo(2008, p. 46):

O professor pesquisador não se vê apenas como um usuário de conhecimento produzido por outros pesquisadores, mas se propõe também a produzir conhecimentos sobre seus problemas profissionais, de forma a melhorar sua prática. O que distingue um professor pesquisador dos demais professores é seu compromisso de refletir sobre a própria prática, buscando reforçar e desenvolver aspectos positvos e superar as próprias deficiências. Para isso ele se mantém aberto a novas ideias e estratégias.

Através do elo entre a prática docente e a pesquisa, uma vez que são determinadas metodologias para o registro e análise dos dados, o professor ganha ferramentas para testagem, implantação e descarte de procedimentos de acordo com os resultados obtidos viabilizando esse plano individualizado necessário para os alunos especiais.

Enquanto responsável por uma equipe de professoras, decidi ouvir as vozes das minhas parceiras de trabalho, adotando essa postura engajada intrínseca ao papel de professora-pesquisadora aqui proposta. Realizei um questionário estruturado em agosto de 2015 para ser respondido por seis docentes do $1^{\circ}$ segmento do Ensino Fundamental da escola particular em que atuo, situada no Rio de Janeiro. O questionário foi composto pelas seguintes perguntas:

1) O que você entende por Educação Inclusiva?

2) Você se sente preparada para a inclusão?

3) Você utiliza o mesmo material didático da turma regular com seus alunos com necessidades especiais?

4) Você tem facilidade em usar tecnologias digitais? Acredita que elas podem auxiliar na Educação Inclusiva?

5) Quais são suas maiores dificuldades para a promoção da Educação Inclusiva?

6) Na sua opinião, qual o papel da família na Educação Inclusiva?

7) Você teve disciplinas sobre Educação Inclusiva na sua formação de professor? Caso sim, acredita que o conhecimento construído foi o suficiente para lhe dar segurança nessa modalidade de educação? 
O objetivo do questionário foi conhecer as crenças e anseios dessas profissionais que atuam na Educação Inclusiva. A análise dos dados obtidos será realizada sob a ótica do paradigma interpretativista, enfatizando os pontos de maior destaque no discurso das professoras participantes da pesquisa.

\section{A VOZ DO PROFESSOR}

Para análise dos dados obtidos, recortaremos as respostas com maior incidência ou relevância, questão a questão, de modo a tentar traçar um panorama geral do que pode ser considerado como crença predominante desse grupo de professoras que possuem tempo de experiência variável na educação. As professoras estão identificadas da seguinte forma:

C. R. - 29 anos de atuação no magistério;

S. M. - 25 anos de atuação no magistério;

C. D. - 10 anos de atuação no magistério;

L. C. - 15 anos de atuação no magistério;

D. V. - 29 anos de atuação no magistério;

S. R. - 15 anos de atuação no magistério.

\section{Análise do questionário}

1) $\mathrm{O}$ que você entende por Educação Inclusiva?

Todas as entrevistadas têm noção, ainda que algumas de forma simplista, do que se trata a Educação Inclusiva. Entre as respostas obtidas destaca-se a oportunidade do convívio social/socialização como um dos principais objetivos para a Educação Inclusiva. $\mathrm{O}$ ensino e a aprendizagem foram citados, contudo destaca-se a colocação de S.M. que mencionou que para os alunos especiais deverão ser elaboradas atividades diferenciadas que abranjam o mesmo conteúdo que está sendo apreendido pela turma, o que condiz com a proposta de adaptação curricular dos PCN-EI.

2) Você se sente preparada para a inclusão? 
A maioria das professoras entrevistadas não se sente preparada para lidar com os desafios da inclusão. Destacam-se entre as justificativas para esse despreparo as dúvidas em relação aos procedimentos a serem adotados e a insegurança. Entre as respostas destaca-se a de S.R., que cita a necessidade da pesquisa e da formação continuada, condizente com o papel de professor-pesquisador (BORTONI-RICARDO, 2008).

3) Você utiliza o mesmo material didático da turma regular com seus alunos com necessidades especiais?

Houve uma divisão em relação às respostas para essa pergunta. Parte das educadoras utiliza o mesmo material e outras não. Ainda há as que utilizam o mesmo material com determinado aluno e com outro não, dentro da mesma classe. Destaca-se o relato de L.C. que, embora tenha tido uma experiência positiva usando o mesmo material didático com todos os alunos, reconhece que devido à heterogeneidade do grupo o mesmo nem sempre é capaz de atingir a todos os alunos da mesma forma.

4) Você tem facilidade em usar tecnologias digitais? Acredita que elas possam auxiliar na Educação Inclusiva?

Metade das entrevistadas demonstrou dificuldades em relação ao uso de tecnologias digitais, embora todas acreditem que as mesmas podem ser aliadas para a Educação Inclusiva. Embora C.D. ache válida a utilização de tais tecnologias, refuta seu uso frequente, sem, no entanto, justificar o porquê. Acredito que um motivo possível seja sua inabilidade com as mesmas, conforme sua afirmação.

5) Quais são suas maiores dificuldades para a promoção da Educação Inclusiva?

Entre as dificuldades apresentadas destacam-se a falta de preparo para lidar com diferentes necessidades, problemas com materiais didáticos, como escassez e sequência, e o cotidiano com o mediador.

Embora a figura do mediador esteja presente no contexto da Educação Inclusiva há algum tempo, é preciso ressaltar que apenas recentemente o artigo $3^{\circ}$ da Lei 12.764/2012, parágrafo único, passou a legitimar o direito ao amparo de um acompanhante especializado, ou agente de apoio à Educação Especial, para os casos em que for comprovada a sua necessidade. É proibido para a escola cobrar taxas extras por 
seus serviços. Ele atua como um profissional de apoio ao professor regente, como um par mais experiente que fornece além de subsídios pedagógicos apoio operacional para os alunos especiais como locomoção e necessidades básicas. Sua atuação deve ser discutida entre família, escola e os profissionais que acompanham o aluno com necessidades especiais.

D.V. cita enquanto aspecto negativo a solicitação de colaboração feita pelo mediador para o engajamento de outros alunos nas atividades realizadas pelo aluno especial, contrapondo-se a essência da inclusão. Em uma perspectiva sociointeracional, a aprendizagem colaborativa traz benefícios para todos os envolvidos no processo educativo. Além disso, um dos propósitos da Educação Inclusiva é também colaborar para a transformação social que ocorre a partir do engajamento das pessoas no bemestar do próximo. Faltaram dados para compreender exatamente qual seria o prejuízo na colaboração entre os alunos, segundo a professora.

Em relação aos materiais didáticos, há uma grande escassez de opções obrigando o professor a utilizar os mesmos materiais para toda a turma. Problemas em relação à sequência dos conteúdos ao término do ano letivo também são evidenciados à medida que as dificuldades vão aumentando com a progressão das séries, principalmente com a fragmentação em mais disciplinas que ocorre a partir do $2^{\circ}$ segmento do Ensino Fundamental. Outra questão também pertinente ao material didático é a contemplação das variadas demandas físicas e mentais dos alunos especiais. São diversas as condições que requerem recursos diferenciados e a escassez de informação e elaboração dificulta ainda mais a decisão e seleção dos conteúdos curriculares e materiais a serem empregados em cada caso.

6) Na sua opinião, qual é o papel da família na Educação Inclusiva?

A importância da família foi citada de forma unânime. Entre as colocações foram citadas a necessidade de uma postura colaborativa por parte da família, mantendo a escola informada quanto o histórico do aluno e também em contato com os profissionais que dão apoio a ele. Foi colocada por S.M. como aspecto importante a aceitação da família quanto à condição da criança especial. É natural que logo após a descoberta da necessidade especial da criança ocorra um período de negação da realidade, o que pode vir a retardar o início do atendimento educacional especializado que esses alunos necessitam. 
7) Você teve disciplinas sobre Educação Inclusiva na sua formação de professor? Caso sim, acredita que o conhecimento construído foi o suficiente para lhe dar segurança nessa modalidade de educação?

As professoras participantes da pesquisa ressaltaram o déficit de disciplinas sobre Educação Inclusiva em sua formação, sendo que quatro das mesmas não tiveram contato nenhum com essas informações durante esse período. As que cursaram disciplinas relacionadas com a Educação Inclusiva julgaram que o conhecimento adquirido não foi suficiente para torná-las seguras em relação às suas práticas. Em algumas das respostas, como a de S.M, ressalta-se a valorização do conhecimento adquirido de forma empírica, através de suas experiências e práticas ao longo de suas jornadas profissionais.

\section{CONSIDERAÇÕES FINAIS}

A escola é um local de apreensão de saberes que só serão relevantes se puderem transcender o mundo da teoria e estabelecer um diálogo com a prática. Durante muito tempo, as pessoas com necessidades especiais sofreram as consequências de uma organização social que preferia não abrir suas portas para elas, fingindo ignorar sua existência. Foram eliminadas na antiguidade, torturadas na idade média e isoladas até bem recentemente (e ainda não o são?). Após séculos e séculos de injustiças e segregação começaram a ter seus direitos assegurados por lei e, agora que conquistaram seu espaço na sociedade, enfrentam o desafio de ressignificar positivamente o conceito de diferença.

O modelo de educação que nos foi apresentado em nossa formação docente, que inconscientemente replicamos, não atende mais às demandas sociais contemporâneas. $\mathrm{O}$ sujeito social hegemônico cede lugar à heterogeneidade, em um novo contexto em que ecoam "as vozes do sul". Desafios para o professor, oportunidades para a reinvenção das práticas pedagógicas: urgência de novas pesquisas, sobretudo no campo da LA.

Como vimos, embora cientes da legitimidade da Educação Inclusiva, uma considerável parcela de professores não se sente preparada para atuar com segurança nessa modalidade transversal do ensino. Embora documentos oficiais como os PCN-EI viabilizem a flexibilização do currículo e o respeito às demandas dos alunos especiais, 
professores enfrentam as dificuldades de uma formação docente deficitária e a escassez de materiais didáticos que possam ser adaptados. Ainda que haja boas intenções, a insegurança é ainda uma grande oponente para a inclusão. Para combatê-la é fundamental a adoção de uma postura investigativa por parte do professor-pesquisador, que ousa, experimenta, refuta táticas mal sucedidas e define quais estratégias melhor se encaixam aos perfis de seus alunos.

Não há uma "receita de bolo" para a Educação Inclusiva, com métodos definidos e com resultados garantidos. Há um vislumbre dos passos iniciais que podemos dar como as adaptações curriculares e o atendimento educacional especializado, mas não há certezas de sucesso. O que temos é a esperança de progressos mediante trabalho árduo e engajado, potencializado pela parceria entre famílias e escola. Educadores lidam com pessoas e pessoas são únicas. Nesse contexto de heterogeneidade que é a sala de aula inclusiva, a diferença que mais importa é a que nós, professores, podemos fazer na vida de nossos alunos e, a partir disso, o que podemos fazer juntos pela sociedade.

\section{REFERÊNCIAS}

BORTONI-RICARDO, S. M. O professor pesquisador: introdução à pesquisa qualitativa. São Paulo: Parábola, 2008.

BRASIL. Ministério da Educação, Secretaria de Educação Fundamental. Parâmetros Curriculares Nacionais: Adaptações curriculares: Estratégias para Educação de alunos com necessidades educacionais especiais. Brasília: MEC/SEF. 1998.

BRASIL. Ministério da Educação, Secretaria de Educação Fundamental. Política Nacional de Educação Especial na Perspectiva da Educação Inclusiva. Brasília: MEC/SEF. 2007

CAT, 2007a. Ata da Reunião III, de abril de 2007, Comitê de Ajudas Técnicas, Secretaria Especial dos Direitos Humanos da Presidência da República (CORDE/SEDH/PR). Disponível em: Acesso em: 11 set. 2010.

CAT, 2007b. Ata da Reunião V, de agosto de 2007, Comitê de Ajudas Técnicas, Secretaria Especial dos Direitos Humanos da Presidência da República (CORDE/SEDH/PR). Disponível em: Acesso em: 11 set. 2010.

CAT, 2007c. Ata da Reunião VII, de dezembro de 2007, Comitê de Ajudas Técnicas, Secretaria Especial dos Direitos Humanos da Presidência da República (CORDE/SEDH/PR). Disponível em: Acesso em: 11 set. 2010.

KENNY, B. For More Autonomy. In: System Vol. 24 nº4. Great Britain. Pergamon: 1993 
MOITA LOPES, L. P. . (Org.). Por uma Linguística Aplicada Indisciplinar. São Paulo: Parábola, 2006

PAIVA, V. L. M . O. A formação do professor para uso da tecnologia. In: SILVA, K.. A.; DANIEL, F. G.; KANEKO-MARQUES, S. M.; SALOMÃO, A. C. B. (Orgs) A formação de professores de línguas: Novos Olhares - Volume 2. Campinas, SP: Pontes Editores, 2013. pg. 209-230.

UNESCO/MINISTÉRIO DA EDUCAÇÃO E CIÊNCIA. Declaração de Salamanca. Necessidades Educativas Especiais - NEE In: Conferência Mundial sobre NEE: Salamanca/Espanha: UNESCO $1994 . \quad$ Disponível em http://portal.mec.gov.br/seesp/arquivos/pdf/salamanca.pdf - Acesso em 21/07/2015

VYGOTSKY, L. S. [1926] Psicologia Pedagógica. Tradução do russo e introdução de Paulo Bezerra. São Paulo: Martins Fontes. 2010

\section{A AUTORA}

Aline Aquino Vieira é Pedagoga (FACIG, 2011), Mestra em Linguística Aplicada (UFRJ, 2014) e Graduanda em Inglês-Literaturas (UNESA). É pesquisadora na área de materiais didáticos, metodologias sociointeracionais, letramento crítico, multiletramentos e múltiplas inteligências. Atua nas áreas de Pedagogia, Pedagogia Inclusiva, Linguística Aplicada, ensino de línguas adicionais, didática do ensino da Língua Inglesa, com ênfase nas abordagens sociointeracionais sob a ótica do pensamento de Vygotsky e Bakhtin. Atualmente é diretora de uma escola da rede particular de ensino.

E-mail: alineaquinovieira@gmail.com 